\title{
Darcy Ribeiro e outros atores: interseções no diálogo França-Brasil
}

\author{
Haydée Ribeiro Coelho I UFMG
}

Resumo: Este estudo destaca o diálogo entre a França e o Brasil a partir do percurso intelectual de Darcy Ribeiro. Para introduzir o tema, émostrado que, segundo Antonio Candido, a literatura brasileira estál ligada à literatura comparada. Isso significa que nossa literatura estabelece relaçoes com outras literaturas e também com a história, a crítica e outros campos de saber. Considerando a especificidade da interlocução entre o Brasil e a França, é possivel verificar que isso ocorre desde os textos de viajantes franceses no Brasil no século XVI. A referência a esse aspecto abre muitos caminhos sobre a literatura, a crítica brasileira e o caráter interdisciplinar entre a Literatura e a Antropologia, ponto central deste ensaio, que trata do diálogo entre a França e o Brasil, já que Darcy Ribeiro foi um antropólogo e romancista. Seu primeiro romance foi traduzido para a lingua francesa e igualmente comentado por muitos jornais da França. Recebeu o titulo de "Doutor Honoris Causa", Universidade de Paris, Sorbonne. Manteve também uma comunicação intelectuale de amizade com Lévi-Strauss, que escreveu muitos livros antropológicos e ainda textos narrativos como Tristes trópicos. Como secretário da Cultura, no governo de Leonel Brizola, no Rio de Janeiro, idealizou a "Casa França-Brasil". Para desenvolver o tema proposto, serão focalizados os seguintes aspectos: na trama do arquivo; a correspondência entre Berta Ribeiro; Darcy Ribeiro e Lévi-Strauss; Darcy Ribeiro na França; viagem, memória e interdisciplinaridade. Para concluir, será abordado o item que trata de "Darcy Ribeiro e a 'Casa França-Brasil". Palavras-chave: Darcy Ribeiro, diálogo intelectual, Brasil-França. 


\title{
Introdução: esboços de diálogo
}

\begin{abstract}
Antonio Candido, em seu estudo sobre literatura comparada, diz:
Há mais de quarenta anos eu disse que estudar literatura brasileira é estudar literatura comparada, porque a nossa produção foi sempre tão vinculada aos exemplos externos, que insensivelmente os estudiosos efetuavam suas análises ou elaboravam os seus juízos tomando-os como critérios de validade. ${ }^{1}$
\end{abstract}

Nesse texto, recupera, historicamente, como isso ocorreu na crítica literária brasileira. A evocação ao artigo do autor de Literatura e sociedade me leva a pensar no caso específico do Brasil em relação à França.

Sob o ponto de vista da história brasileira, a interseção cultural entre ambos os países pode ser observada nos textos que instauraram uma representação imaginária sobre nós. A propósito desse momento, é importante destacar a $A$ fundação do Brasil, ${ }^{2}$ volume organizado por Darcy Ribeiro e Carlos de Araújo Moreira Neto que, "elaborado a pedido da Biblioteca Ayacucho, da Venezuela, comemora os 500 anos da chegada do europeu nas Américas". 3

Darcy Ribeiro e Carlos de Araújo Moreira Neto "se conheceram no Rio de Janeiro, no Museu do Índio, em meados da década de 1950”. Conforme ainda a antropóloga Gisele Jacon de Araújo Moreira, a partir desse momento, "mantiveram uma parceria produtiva como antropólogos críticos e combativos, compartilhando o interesse pelos índios e pelo conhecimento do Brasil".

Do volume decorrente da parceria entre os dois antropólogos, ressalto a seleção realizada por eles dos seguintes autores franceses e respectivos capítulos e textos: Yves d'Evreux ("Ordem e respeito que a natureza pôs entre os selvagens e que é observada inviolavelmente pela juventude" (Capítulo XXI) e "Da consangüinidade existente entre esses selvagens" (capítulo XXIII) do livro Continuação das coisas mais memoráveis ocorridas no Maranhão nos anos de

1. CANDIDO. Literatura comparada, p. 211.

2. RIBEIRO; MOREIRA NETO. A Fundação do Brasil. Testemunhos. 15001700 .

3. RIBEIRO; MOREIRA NETO. Fundação do Brasil. Testemunhos. 15001700 , p. 3.

4. MOREIRA. Fazimentos. Carlos Moreira Neto, p. 3. 
1613 e 1614; André Thevet ("Da sepultura e demais cerimônias mortuárias dos selvagens" (capítulo XLIII), de Singularidades da França Antártica); Jean de Léry ("O que podemos chamar de leis e policiamento entre os selvagens; modo por que tratam os visitantes amigos; prantos e discursos festivos das mulheres por ocasião das boas-vindas", de Viagem à terra do Brasil); Claude d'Abbeville ("Gênero e temperamento dos maranhenses", retirado de História da Missão dos Padres Capuchinhos na ilha do Maranhão e terras circunvizinhas) e Michel de Montaigne ("Dos canibais"), capítulo de Ensaios.

A menção a esses textos abre outros caminhos para considerações sobre a literatura, a crítica "brasileira" e o caráter interdisciplinar entre Literatura e Antropologia, a partir do qual o tema da viagem e seus desdobramentos encontram um filão rico de possibilidades.

Os textos de fundação de franceses e portugueses ligam o mar do personagem Miramar ao de Oswald de Andrade, gerando aquele de Antonio Candido sobre "Oswald viajante". Paris, a capital cultural que uniu o Brasil e a França e os latino-americanos na época das vanguardas europeias, possibilitando uma comunicação internacionalizada e cosmopolita, foi um dos objetos do livro Vanguarda e cosmopolitismo de Jorge Schwartz.

Silviano Santiago, em Viagem ao México, de modo ficcionalizado, valendo-se de um novo meio de reprodutibilidade técnica, dialoga com Antonin Artaud em outro tempo e espaço:

Fui então anotando e gravando neste computador as frases que começam a jorrar aos borbotões da boca falastrona de Artaud. Julguei corretamente que estava encerrada a época de silêncio dele e de ansiedade minha. Podia finalmente dar início ao projeto do romance que vinha me atormentando por mais de uma década.

Os encontros entre culturas e olhares diferenciados sobre elas instauram um campo importante de estudo como aquele entre Literatura, Antropologia e crítica literária sob a perspectiva dos antropólogos. Em "O pluralismo de Antonio Candido",

5. Cf. CANDIDO. Oswald viajante, p. 53-56.

6. Cf. SCHWARTZ. Vanguardas enfrentadas.

7. Santiago. Viagem ao México, p. 27. 
Mariza Peirano mostra o percurso acadêmico do crítico que transitou da Antropologia e da Sociologia para a crítica literária. No final do artigo, comenta:

Não é possível refazer a história mas é possível recuperar a história. E recuperando-se a história, podemos trazer Antonio Candido para o convívio dos antropólogos, olhando o seu "pluralismo" como uma afirmação das preocupações atuais da disciplina e a sua crítica literária como caminho para uma Antropologia da vida intelectual brasileira. ${ }^{8}$

Em Conta de mentiroso, ${ }^{9}$ Roberto DaMatta desenvolve as relações entre Literatura e Etnografia, considerando a obra literária como fonte etnográfica. $O$ aspecto interdisciplinar de seu enfoque é reiterado em outro artigo, ${ }^{10}$ publicado numa coletânea da revista Tempo Brasileiro, em número totalmente dedicado à interdisciplinaridade. Em Aprender Antropologia, ${ }^{11}$ François Laplantine evidencia a importância da experiência nascida com o outro e o relacionamento entre Literatura e Antropologia, pois o trabalho de campo constitui uma de suas atividades. Essas observações desdobram-se em outras tramas nascidas de outras fontes como os arquivos.

\section{$\mathrm{Na}$ "trama do arquivo": ${ }^{12}$ correspondência entre Berta Ribeiro, Lévi-Strauss e Darcy Ribeiro}

A crítica genética e o estudo dos arquivos têm possibilitado abordagens que vão além da análise intrínseca do texto, dos aspectos escriturais, incluindo evidentemente aqueles intertextuais. Nesse sentido, a correspondência tem sido um aliado importante nessas pesquisas, esclarecendo elementos da recepção e da produção de um autor. Recupera, ainda, o sujeito biográfico, elucidando diálogos que vão além da simples troca entre missivistas. A relevância do estudo de correspondência entre intelectuais desencadeou a publicação de missivas por parte de

8. PEIRANO. Uma antropologia no plural: três experiências contemporâneas, p. 49.

9. DAMATTA. Conta de mentiroso.

10. DAmatTA. Conta de mentiroso, p. 35-89.

11. LAPLANTINE. Aprender Antropologia.

12. A expressão "trama do arquivo" foi extraída da obra organizada por Wander Melo Miranda, A trama do arquivo. 
autores $^{13}$ e críticos, ${ }^{14}$ tornando-se objeto de estudo de dissertações e teses acadêmicas. Essas considerações fornecem subsídios para as considerações que se seguem.

Em 7 de março de 1969, Berta Ribeiro, antropóloga e esposa de Darcy Ribeiro, envia uma carta a Lévi-Strauss, dando-lhe informações sobre o retorno de Darcy Ribeiro ao Brasil (ocorrido em 30 de dezembro de 1968), depois de ter ficado exilado no Uruguai. Comunicava, também, ao antropólogo francês que Darcy Ribeiro estava preso desde o dia 13 de dezembro de 1968, por ocasião do Ato Institucional n. 5 "que liquidou, praticamente, com as garantias jurídicas com que ainda contávamos". ${ }^{15}$ Berta Ribeiro solicitava ao autor de Tristes trópicos uma ajuda para "aliviar" a situação do marido. A manifestação de solidariedade poderia ser expressa por meio de "um telegrama ao Presidente da República ou uma nota em algum prestigioso jornal parisiense, junto com uma nota biográfica”. . Dizia ainda que dados "pessoais sobre Darcy Ribeiro podiam ser encontrados também no prefácio de Betty J. Meggers ao The civilizacional Process." ${ }^{17}$

Não encontrei a resposta dessa carta nos arquivos consultados da "Fundação Darcy Ribeiro". Naturalmente, Lévi-Strauss não só respondeu como também enviou à Berta um recorte do jornal Le Monde, em que aparece a notícia do encarceramento do autor de Maíra, seguida de dados biográficos. No final da notícia, com letra de próprio punho, Lévi-Strauss anota o nome do jornal, o dia e a página. ${ }^{10}$

Anterior a essa carta, enviada por Berta Ribeiro a Lévi-Strauss, encontrei mais outras que evidenciam como o antropólogo francês se correspondeu com Darcy Ribeiro, havendo interesse pela obra antropológica de ambas as partes. Em 28 de outubro de 1952, em papel timbrado da École Pratique des Hautes Études (Sorbonne), Paris, Claude Lévi-Strauss agradece Darcy Ribeiro pelo envio do livro A arte dos indios Kadiuéu, noticiando ao remetente a compilação, realizada em Nalike, de "plusieurs centaines de dessins originaux, en tous points comparatifs

13. SABINO; LISPECTOR. Cartas perto do coração. Fernando Sabino e Clarice Lispector.

14. Gomes. Cartas em foco: Clarice Lispector e o teatro, p. 97-124.

15. CARTA de Berta Ribeiro a Claude Lévi-Strauss. Toda a correspondência, a ser comentada, foi consultada na Fundação Darcy Ribeiro, Rio de Janeiro.

16. CARTA de Berta Ribeiro a Claude Lévi-Strauss.

17. CARTA de Berta Ribeiro a Claude Lévi-Strauss.

18. Cf. LE MONDE. Le professeur Darcy Ribeiro est incarcéré depuis trois mois dans une Forteresse de Rio, p. 4. 
aux vôtres". 19 Esclarece-lhe que infelizmente estavam inéditos a não ser aqueles publicados em dois artigos, "Fards indiens", "Le dédoublement de la représentation dans les arts de l'Asie et de l'Amérique".

Tomando conhecimento do trabalho de Darcy Ribeiro sobre os Kadiuéu, manifesta o desejo de reunir "tous les documents existants sur l'art kadiueu dans une vaste publication". ${ }^{22}$ Pensava justamente, com Darcy Ribeiro, em "constituer un Trésor de l'art kadiueu qui serait une publication capitale pour l'ethnologie américaine".

Em 2 de janeiro de 1953, o autor de Maíra, responde a Lévi-Strauss, dizendo:

Acho magnífica sua idéia de publicar um Tesouro da Arte Kadiuéu e quero colocar meu material à sua disposição. Esse é um trabalho em que eu poderei colaborar, mas que deverá ser feito sob sua direção, em respeito à sua prioridade no estudo das artes dos Kadiuéu.

(...)

O material que colhi pertence à Secção de Estudos do SPI onde estou organizando o Museu do Índio e consiste em um milhar de desenhos, uma dezena de couros pintados e uma coleção de cerâmica bem representativa do momento atual dos Kadiuéu. ${ }^{24}$

19. LÉVI-STRAUSS. Carta de Claude Lévi-Strauss a Darcy Ribeiro."Várias centenas de desenhos originais, em todos os pontos comparativos aos seus". (Traduções da autora, exceto quando explicitamente referido).

20. LÉVI-STRAUSS. Carta de Claude Lévi-Strauss a Darcy Ribeiro, 28 out. 1952, Paris. A propósito do artigo mencionado, a única referência bibliográfica que aparece na correspondência é: vvv, n. 1, New York, 1942.

21. LÉVI-STRAuSS. Carta de Claude Lévi-Strauss a Darcy Ribeiro, 28 out. 1952, Paris. A respeito do artigo mencionado, tem-se a informação de que o artigo foi publicado em Renaissance, v. 2 et 3, New York, 1944-45.

22. LÉVI-STRAuSs. Carta de Claude Lévi-Strauss a Darcy Ribeiro, 28 out. 1952, Paris. "Todos os documentos existentes sobre a arte kadiueu em uma vasta publicação".

23. LÉVI-STRAUSS. Carta de Claude Lévi-Strauss a Darcy Ribeiro. "Constituir um Tesouro da arte kadiueu que seria uma publicação capital para a etnologia americana".

24. CARTA de Darcy Ribeiro a Claude Lévi-Strauss em português. 
Em 20 de setembro de 1954, Lévi-Strauss, em correspondência destinada a Darcy Ribeiro, atesta que recebeu uma carta-convite dirigida à senhora Simone Roche e aquela que lhe foi "destinée directement". 25 antropólogo francês dizia que faria todos os esforços, junto ao "Centre National Français de la Recherche Scientifique", para "obtenir une participation française à une recherche dont l'intérêt international est évident et à laquelle les sentiments d'amitié très profonds que j'ai conservés pour le Brésil ajoutent un prix supplémentaire". ${ }^{26}$

Na última carta que encontrei de Lévi-Strauss para Darcy Ribeiro (datada em 19/.../1980), ${ }^{27}$ o intelectual francês agradecia o livro que the tinha sido enviado (não fica claro qual deles). Dizia ao colega e amigo brasileiro que se ele estivesse ainda em janeiro, em Paris, que se comunicasse com ele. Teria o maior prazer em recebê-lo. Deseja-lhe, no final da carta, escrita de próprio punho, um feliz ano novo. O tom amigável demonstra que eles não dialogavam apenas como dois colegas de profissão.

Os fragmentos da correspondência entre Berta Ribeiro, Darcy Ribeiro e Lévi-Strauss sinalizam para os seguintes aspectos: Claude Lévi-Strauss foi um elo importante para denunciar a situação de encarceramento de Darcy Ribeiro junto à comunidade internacional; os dois intelectuais tinham conhecimento das respectivas obras; as trocas intelectuais foram regidas pelo respeito, ética e admiração. Nesse caso específico, não ocorreu o que Pierre Rivas afirma, "a desigualdade dos termos da troca", em relação às sociedades dependentes. Caminhando por outros meandros, há a necessidade de tratar as especificidades dos diálogos para não incorrer apenas nas generalizações. O estudo da correspondência entre intelectuais de "sociedades dependentes" e sociedades "independentes" pode explicitar outro cenário cultural no universo dos intercâmbios e diálogos

25. LÉVI-STRAUSS. Carta de Claude Lévi-Strauss a Darcy Ribeiro. "destinada diretamente".

26. CARTA de Lévi-Strauss para Darcy Ribeiro.

27. Observo que não está legível o mês da carta enviada. (Consulta Fundação Darcy Ribeiro).

28. RIVAS. Diálogos interculturais, p. 81. 


\section{Darcy Ribeiro na França}

Os anos se passaram. Darcy Ribeiro foi libertado da Fortaleza de Santa Cruz e, sob novas ameaças, entre exílios e retornos ao Brasil, em 1979, recebe, no Salão Nobre da Sorbonne, o título de "Doutor Honoris Causa" da Universidade de Paris. Em Testemunho, fala do desafio da escrita do discurso:

O desafio foi quase paralisante. De fato nunca tive tanta dificuldade de escrever um discurso. Dois eram os obstáculos. Por um lado, não queria fazer o elogio da Sorbonne em seu papel de suposta avó das universidades ou de mãe fecunda da cultura ocidental. Tendo planejado a universidade de Brasília, repensando a universidade desde a raiz, não podia cair em basbaquices. A outra dificuldade era não fazer elogio da antropologia francesa, especialmente de Lévi-Strauss, tão admirado e papagaiado por toda parte, principalmente aqui, por uma antropologia desumana, insensata e infiel. ${ }^{29}$

À parte à retórica discursiva de todo texto, é importante assinalar a consciência do autor brasileiro no que se refere à mudança de perspectiva crítica e teórica em relação ao conhecimento produzido pelos países marcados historicamente pela colonização europeia. Contemporaneamente, o crítico Walter Mignolo destacou a importância de Darcy Ribeiro no âmbito do que ele denominou de "epistemologia fronteiriça".

A presença de Darcy Ribeiro na França tem outras faces como aquela relacionada à recepção de Maíra. Acompanhar esse aspecto em distintos níveis desde a tradução até sua fortuna crítica nas universidades francesas seria tarefa para outros estudos. Nesse sentido, quero apenas destacar alguns fragmentos interpretativos, presentes em periódicos, resultantes da tradução de Maíra por Alice Raillard, que, na contracapa do livro, explica a mudança de Maíra por Maïra:

Maíra doit se lire Maïra: la disparate d'orthographe adoptée pour ce nom sur la page de titre et dans le corps de l'ouvrage souligne un problème traditionnel de transcription. On hésite entre la fidelité a l'oeil et à la

29. RIBEIRO. Testemunho, p. 13.

30. MigNOLO. Espacios geográficos y localizaciones epistemológicas o la ratio entre la localización geográfica y la subalternización de conocimientos, p. 91-106. 
fidelité a l'oreille. Les choix - divers de la traduction ont tenu compte de cette double nécessité. S'ajoute ici le fait que des mots indiens hérissent d'étrangeté le texte même. Les termes, indiens ou brésiliens, conservés dans les textes français sont expliqués dans un glossaire à la fin de livre. ${ }^{31}$

Destaco as seguintes palavras do glossário do livro traduzido, originadas do tupi: ambir; anhangá; anhé; anhereté; anum; avá; carapuá; carimã; cauím; chibé; coati; cunantã; cuupira; gabiroba; itã; jacuí; jatobá; javari; jub-solar; mingau; mirixorã; paca; pajé-sacacá. Existem muitas outras que são do tupi-guarani; do dialeto kadiuéu e do bororo. Por meio do glossário, fica claro que a tradução por si é um meio de conhecer o outro. Nesse caso, o livro brasileiro, lido em francês, introduz na língua francesa um plurilinguismo que provoca uma reflexão sobre a diferença cultural que se impõe como marca, como traço que não se pode apagar e ser ignorado pela cultura ocidental.

Alice Raillard, a tradutora de Maíra, faz uma longa apresentação de Darcy Ribeiro em "Le sentiment d'être indien", 32 mesclando informações bibliográficas, fragmentos de Maíra traduzido em francês e, ainda, trechos de entrevista com o autor brasileiro, de modo que o leitor francês tome conhecimento da obra e do autor que também é antropólogo. Essa relação entre dados biográficos e obra está presente nos mais diferentes comentários críticos nas matérias consultadas dos periódicos. Em alguns deles é rememorado o discurso de Darcy Ribeiro na Sorbonne.

A respeito do glossário e da tradução, cabe-me assinalar a posição de Jean-Michel Gardair:

Le lecteur aurait tort de se laisser décourager de prime abord par leur étrangeté. Au bout de deux ou trois chapitres il n'aura même plus besoin

31. RAILLARD. Le sentiment d'être indien. "Maíra se deve ler como Maïra: a dessemelhança de ortografia adotada para esse nome no título e no corpo da obra acentua um problema tradicional de transcrição. Hesita-se entre a fidelidade ao olhar e a fidelidade ao ouvido. As escolhas diversas da tradução levaram em consideração essa dupla necessidade. Acrescentase aqui o fato de palavras indígenas sobrecarregarem de estranheza o texto. Os termos, indígenas ou brasileiros, mantidos nos textos franceses são explicados em um glossário no fim do livro."

32. RAILLARD. Le sentiment d'être indien. 
du petit glossaire qui figure en fin de volume. Le roman de Darcy Ribeiro est à lui-même son propre dictionnaire. Un dictionnaire vivant. ${ }^{33}$

A propósito de alguns trechos interpretativos sobre o romance, assinalo mais alguns outros:

Maïra, merveilleusement traduit du portugais, est une sorte d'ethnologie narrative qui démontre et démonte les mécanismes insidieux de l'ethnocide. ${ }^{34}$

Voici un livre unique, car il donne à entendre la voix des indiens d'Amazonie, le cri d'une civilisation agonisant faute de pouvoir s'adapter aux normes technologiques de notre société. Les Indiens de Maïra ne sont pas de "bons sauvages" mais bien des hommes d'aujourd'hui, en situation de transhumance culturelle entre deux civilisations dont chacune exclut l'autre.

Bref, une sorte de roman vérité à l'écriture sensuelle, une sonnette d'alarme et presque un testament ethnographique. ${ }^{36}$

33. GARDAIR. Nos ancêtres les Indiens. "O leitor enganar-se-ia, desencorajando-se primeiramente pela sua estranheza. Ao final de dois ou três capítulos, não terá mais necessidade do pequeno glossário que figura no fim do volume. O romance de Darcy Ribeiro é ele mesmo seu próprio dicionário, um dicionário vivo."

34. DIBIE. La grande messe de l'ethnologie. "Maíra, maravilhosamente traduzido do português, é uma espécie de etnologia narrativa que mostra e desmonta os mecanismos insidiosos do etnocídio."

35. DesCAmps. La Gazette de la région du Nord. "Eis um livro único, porque dá a compreender a voz dos indígenas da Amazônia, o grito de uma civilização agonizante impossibilitada de se adaptar às normas tecnológicas de nossa sociedade. Os indígenas de Maíra não são 'bons selvagens', mas homens de hoje, em situação de transumância cultural entre duas civilizações onde cada uma exclui a outra."

36. GILLES. Grandeur et décadence d'une tribu d'Amazonie. A mi-chemin entre le roman et l'ethnologie. "Sumariamente, uma espécie de romance verdade com uma escritura sensual, uma campainha de alarme e quase um testamento etnográfico." 
Livre-fleuve. Livre-jungle. Avec "Maïra", il faut prendre les métaphores au pied de la lettre. Le fleuve est là, la jungle aussi, dans ce haut pays amazonien où subsistent encore - mais pour combien de temps - quelques tribus d'Indiens.

(...)

Le Brésil-fleuve, le Brésil-jungle de Darcy Ribeiro est à des années-lumière de celui de Jorge Amado. Il y a entre eux toute la distance qui sépare les plateaux les plus réculés du Mato Grosso des rivages atlantiques de la province de Bahia. Qui sépare la lente agonie des indiens mairuns de l'explosion de vitalité du petit peuple du Salvador. La dénonciation de l'ethnocide, l'apologie du métissage.

É importante dizer que Jorge Amado foi um dos autores brasileiros mais divulgados na França. Sua recepção crítica, envolvendo aspectos étnicos e políticos, foi analisada de forma detalhada por Pierre Rivas, que, no final de seu estudo, demonstra como Jorge Amado contribuiu para que a Bahia também fizesse parte da mitologia literária das cidades inconfundíveis.

Em uma entrevista, concedida a Les Nouvelles Littéraires, o escritor brasileiro, ao falar sobre a gênese de seu primeiro romance, comenta:

Ce roman ne signifie pas que je ne continuerai pas mes travaux scientifiques. Je n'ai pas essayé d'écrire une œuvre de fiction sur les Indiens, mais de me mettre dans la peau d'un indien. Je me considère comme un anthropologue atypique. M'intéresse le processus auquel ils sont soumis, et j'en suis participant. C'est ma théorie de Berlin sous les bombes: il ne serait jamais venu à l'esprit de quiconque de parler de

37. VITOUX. La jungle à feu et à sang. Pour combien de temps encore les Indiens d'Amazonie verront-ils se lever le soleil?. "Livro-rio. Livro-floresta. Com Maíra, é preciso tomar as metáforas ao pé da letra. O rio está lá, a floresta também, nesse alto país amazônico onde subsistem ainda - mas por quanto tempo? - algumas tribos de indígenas."

(...)

"O Brasil-rio, o Brasil-floresta de Darcy Ribeiro está há anos-luz daquele de Jorge Amado. Há entre eles uma distância equivalente à que separa os planaltos os mais recuados do Mato Grosso das praias atlânticas do estado da Bahia; à que separa a lenta agonia dos indígenas mairuns da explosão de vitalidade de Salvador. A denúncia do etnocídio, a apologia da mestiçagem." 
musique sans tenir compte des bombardements. Lévi-Strauss, par exemple, oublie les bombes. D'autres anthropologues, en faisant abstraction de ce qui arrive aux Indiens, s'en font les gigolos. ${ }^{38}$

A imprensa francesa também se interessou pela recepção de Maíra no Brasil. A propósito desse aspecto Darcy Ribeiro responde:

La parution de Maïra a donné lieu à bien des débats. Des analyses structuralistes m'ont révelés des choses que je n’y avais pas mises! Un critique a rattaché mon roman à la lignée du bon sauvage, issue de Chateaubriand. Des théologiciens y ont vu une sorte de transfiguration de textes sacrés. Les psychanalystes, eux, se sont penchés sur le mythe du vagin denté. Etc. En fait, bien des gens ont été frappés de ce que ce livre ne s'inscrit pas dans une tradition judéo-chrétienne de la mort et de l'amour, puisque la mythologie maïrun veut que Dieu lui-même soit descendu sur Terre pour faire l'amour! $!^{39}$

Sobre a recepção da literatura brasileira na França, é importante destacar a opinião de Mário Carelli, tendo em vista que está registrada no Jornal do Brasil, justamente no ano em que ocorre a tradução de Maíra na França:

38. RIBEIRO. Je me suis mis dans la peau d'un indien. Entretien avec Jean François Chaix. "Esse romance não significa que não continuarei meus trabalhos científicos. Não tentei escrever uma obra sobre os índios, mas me meti na pele de um indígena. Considero-me como um antropólogo atípico. Interesso-me pelo processo a que são submetidos, e sou participante disso. É minha teoria de Berlim sobre as bombas: não teria jamais passado no espírito de alguém falar de música sem levar em conta os bombardeamentos. Lévi-Strauss, por exemplo, esquece as bombas. Outros antropólogos fazendo abstração do que ocorre aos indígenas, tornam-se seus gigolôs."

39. RIBEIRO. Je me suis mis dans la peau d’un indien. Entretien avec Jean François Chaix. "O lançamento de Maíra deu lugar a muitos debates. Análises estruturalistas revelaram-me coisas que jamais coloquei no livro. Uma crítica associou meu romance ao tema do bom selvagem, na linha de Chateaubriand. Teólogos viram uma espécie de transfiguração de textos sagrados. Os psicanalistas voltaram-se para o mito da vagina dentada, etc. Com efeito, muitos consideraram que esse livro não se inscreve em uma tradição judaico-cristã da morte e do amor, já que a mitologia mairum diz que Deus desceu sobre a Terra para fazer amor." 
Eu diria que o discurso francês sobre a América Latina está diferente. Não é mais discurso econômico sobre mercado de trabalho, mão-deobra barata, a obsessão puramente mercantil. Há uma atenção maior dada à realidade viva dos países. E que pode ser visualizada no ato simbólico de convidar-se para a posse do Presidente escritores como Garcia Marquez ou Jorge Amado.

(...)

A arbitrariedade na escolha de títulos talvez seja outra das razões que entravam a conquista do público francês pela literatura brasileira. Nem sempre o critério usado é o do valor literário. Há normalmente uma predileção do exotismo temático. Um critério que justifica Maíra, mas não encontra eco em Osman Lins ou em Clarice Lispector.

Pelas posições interpretativas divulgadas em periódicos especializados e na grande imprensa, verifica-se que o estranhamento (o exotismo) está presente em algumas críticas levantadas, mas não é o simples exotismo em si que chamou a atenção dos críticos franceses para o primeiro romance do antropólogo brasileiro.

Relacionado ao exotismo temático, Pierre Rivas apresenta uma posição semelhante à de Mário Carelli, quando se refere ao aparecimento de Macunaíma na França:

Tratando-se de um romance latino-americano na França, partiremos dos etnotipos culturais que se aproximam dos estereótipos. Macunaíma aparece na França em 1979, numa coleção específica da Flammarion, dedicada à América Latina, a Collection Barroco. Este tipo de nominação já induz uma tipologia literária e um contrato de leitura; define um campo discursivo específico, que conotaria o conjunto literário latino-americano (o barroco como ethos sulamericano), um idioleto configurativo (a escritura barroca como estilo desta literatura) e um momento crítico (o neobarroco teorizado por certos escritores latino-americanos que vivem na França, particularmente Severo Sarduy, que retoma Lezama Lima). ${ }^{41}$

A leitura de Tristes trópicos e a publicação de Saudades do Brasil em 1994 abriram-me a possibilidade de reflexão sobre a viagem, a memória e a interdisciplinaridade, pontos comuns nas trajetórias de Darcy Ribeiro e Claude Lévi-Strauss.

40. WYLER. Abertura, o livro brasileiro amplia o seu espaço na programação das editoras francesas, [s.p].

41. RIVAS. Diálogos interculturais, p. 88-89. 
Viagem, memória e interdisciplinaridade: Lévi-Strauss e outros diálogos

Como já estudei o resgate da memória indígena pelas viagens ocorridas em Maíra, ressalto que o romance de Darcy Ribeiro dialoga com as viagens do século XVI (olhares fundantes do Brasil); com a dos exilados brasileiros da década de 1970, com aquelas dos neocolonizadores e, ainda, com os relatos de viagem do século XX. Sob esse último enfoque, incluo Tristes trópicos.

Tratar da Literatura e da Antropologia, por meio da viagem e da memória em Lévi- Strauss, parece redundante e mesmo desnecessário, já que há um trabalho como o de Fernanda Massi ${ }^{42}$ que evidenciou como Lévi-Strauss rompe com uma tradição etnográfica sobre os relatos e de que maneira se antecipou a uma crítica antropológica atual, preocupada com a textualidade dos ensaios antropológicos e com a escrita desses novos estudos, voltados para o dialogismo, termo que a Antropologia se apropriou a partir da crítica literária de Mikhail Bakthin. No entanto, cabe-me retomar alguns aspectos para que possa explicitar, no âmbito da crítica literária atual, a passagem da Antropologia para a Literatura e destacar o aspecto intersticial dos discursos tanto antropológicos quanto literários, mencionando autores e textos cujas afinidades e diferenças foram sendo mostradas nesse percurso cujo centro repousa nas interseções e diálogos entre o Brasil e França, tendo em vista a figura de Darcy Ribeiro e outros atores importantes como Carlos de Araujo Moreira Neto, Berta Ribeiro e Lévi-Strauss.

Em Tristes trópicos, Lévi-Strauss faz sua travessia, conta-nos seu nascimento como etnólogo, realiza uma passagem do relato antropológico para a Literatura. O livro escrito, depois da Segunda Guerra Mundial, revela sua experiência de antropólogo, ocorrida durante a guerra, cujas marcas estão no enfrentamento das dificuldades reais de ultrapassar as fronteiras geográficas da Europa até à América.

No âmbito da intelectualidade francesa, a recepção crítica de Tristes trópicos (publicado em 1955, praticamente vinte anos depois de suas viagens, inclusive as que fez ao Brasil) foi bastante variada. Em De perto e de longe, Didier Eribon, por meio de uma entrevista com Lévi-Strauss, mostrou essas diferentes reações que me parecem muito importantes pelo alcance que elas têm como objeto de reflexão sobre esse trânsito que Lévi- Strauss realiza entre a Antropologia e a Literatura. Nessa entrevista, Lévi-Strauss, em relação à publicação de Tristes

42. MASS. O nativo e o narrativo I, p. 187-198. 
trópicos, diz que "sentia remorso por não estar trabalhando no segundo volume sobre as estruturas complexas de parentesco". Entre os romancistas e os representantes da crítica literária, o livro teve uma acolhida calorosa nos artigos de Leiris, Blanchot, George Bataille e Raymond Aron. E, no meio universitário, entre os etnólogos, a "acolhida foi mais reservada".

Esse fato, também comentado por Fernanda Massi, tem um alcance muito amplo. Ele demonstra, a meu ver, como uma corrente de antropólogos, nesse momento, estava presa à demarcação entre os discursos. Por outro lado, revela também de que maneira os representantes da crítica literária e os ficcionistas estavam abertos para a derrubada das fronteiras discursivas. Nesse caso, é preciso refletir sobre a obra e a expectativa do leitor. Para um tipo de leitor preso à demarcação entre os saberes, um trabalho escrito por um etnólogo só poderia tratar de Etnologia a partir de uma metodologia científica. Em Tristes trópicos, Lévi-Strauss rompe com esse tipo de expectativa. O viajante moderno "corre atrás dos vestígios de uma realidade desaparecida".

O estudo da viagem e da memória em Lévi-Strauss é sobretudo um trabalho de linguagem e de discurso. Dentre as várias imagens que Lévi-Strauss constrói, gostaria de me fixar, inicialmente, em algumas daquelas de que se vale para se reportar à viagem e à memória.

Lévi-Strauss, na primeira parte do livro, "O fim das viagens", no capítulo "Em busca do poder" situa-se entre o "viajante antigo" e o "viajante moderno". No primeiro caso, "confrontado com um espetáculo prodigioso", tudo passa despercebido. O viajante moderno "corre atrás dos vestígios de uma realidade desaparecida".

Para Lévi-Strauss, "arqueólogo do espaço", as recordações foram trazidas pelos destroços. Nas palavras do autor, "as arestras reduzem-se, seções inteiras desmoronam-se, os momentos e os lugares entrechocam-se; justapõem-se ou invertem-se tal como acontece com os sedimentos deslocados por tremores de uma crosta envelhecida". O movimento da memória, comparado ao da terra, pressupõe uma ação de maneira dupla: a geografia do "eu" desenha a terra e o

43. DIDIER. De perto e de longe, p. 79-80.

44. DIDIER. De perto e de longe, p. 80.

45. LÉVI-STRAUSS. Tristes trópicos, p. 36.

46. LÉVI-STRAUSS. Tristes trópicos, p. 37. 
"eu", pelo saber geológico/geográfico, desenha o vivido. A geografia espacial, projetada no "eu" pela viagem, ao alongar o seu "istmo" entre o "eu" e a vida, ${ }^{47}$ permite, paradoxalmente, que os fragmentos, transformados em escrita, venham preencher, de forma lacunar, os vestígios da realidade, dos homens e de outras paisagens desaparecidas ou prestes a desaparecer.

Pela memória, a viagem do etnólogo torna-se singular. Há ruptura com uma cronologia, ocorre uma justaposição de planos narrativos, a viagem e a memória assemelham-se ao deslocamento da terra e ao deslocamento geográfico e temporal. Na narração do "eu" incluem-se histórias, fios de histórias relacionados ao "eu" e ao "outro". As afinidades literárias do intelectual francês e sua formação múltipla e interdisciplinar vão compondo sua etnologia e sua memória.

Na reconstrução do mundo perdido, sua experiência como etnólogo no Brasil é de fundamental importância. A desmitificação da viagem exótica, em relação ao Brasil, começa pelos sentidos olfativo e visual. O Brasil é sentido como "perfume queimado", e o índio "pobre caça apanhada nas armadilhas da civilização mecânica". As viagens atuais, segundo ele, são os "nossos excrementos lançados à fase da humanidade". ${ }^{50}$ A morte, contida nessas associações, impulsiona o autor de Saudades do Brasilà reconstrução dos mitos, de histórias, da arte e do saber indígenas.

Não poucas vezes, o olhar sobre o outro é atravessado por associações pertencentes à cultura ocidental de onde o etnólogo se originou. Para ilustrar esse aspecto, tomo um exemplo extraído de Tristes trópicos. Depois da simulação de uma cerimônia ritualística da morte, entre os bororos, o autor faz o seguinte comentário: "Por uma maneira de andar temerosa e hesitante, exprimiam admiravelmente a sua natureza de sombras; pensei em Homero, em Ulisses, retendo a custo os fantasmas conjurados pelo sangue." N1 Nesse caso, a etnologia e a experiência literária do autor evidenciam que a visão diante do outro está marcada pelo olhar europeu.

A travessia, empreendida pelo etnólogo contra a morte e a favor da preservação cultural do outro, permanece em Saudades do Brasil, ${ }^{52}$ livro que

47. LÉVI-STRAUSS. Tristes trópicos, p. 37.

48. LÉVI-STRAUSS. Tristes trópicos, p. 42.

49. LÉVI-STRAUSS. Tristes trópicos, p. 35.

50. LÉVI-STRAUSS. Tristes trópicos, p. 37.

51. LÉVI-STRAUSS. Tristes trópicos, p. 225.

52. LÉVI-STRAUSS. Saudades do Brasil. 
contém outras fotografias sobre os índios e o Brasil de 1935, além daquelas de Tristes trópicos. A publicação desse livro representa mais uma vez a luta do autor contra o esquecimento, contra a impossibilidade de olhar novamente o que se viu e de refazer caminhos já percorridos. A revelação do seu arquivo pessoal, depois de tanto tempo (entre a publicação de Tristes trópicos e Saudades do Brasil), é um gesto de reconstrução de uma memória particular, mas ao mesmo tempo coletiva. Na medida em que tira nosso retrato dos seus guardados, nos reconstrói e nos constitui no presente. Também tira do arquivo parcela de sua vida, narrada em Tristes trópicos.

$\mathrm{Na}$ análise comparativa entre Tristes trópicos e L'Afrique fantôme, de Michel de Leiris, Fernanda Massi mostra como esses textos antecipam-se à crítica americana pós-moderna em decorrência do questionamento do trabalho antropológico em campo e dos desafios colocados pela produção do texto antropológico. Acredito que esse comentário possa se estender ao romance Maíra e explicita, de certa forma, a passagem de Darcy Ribeiro da Antropologia para a Literatura.

Em Maíra, o índio conta sua própria história (apesar, é claro, da mediação entre autor e personagem). As histórias da tribo são relatadas não só por Isaías, mas por meio do deus Maíra, que, se despojando de onisciência, convertida em ato de possessão, dá voz aos mairuns, que contam histórias do passado e do presente. Na medida em que Darcy Ribeiro constata que seu livro revela mais sabedoria sobre os índios que toda sua Antropologia, tem consciência do poder da palavra como arma de que dispõe para revelar a vida e a morte dos índios, narrada de dentro da cultura do "Outro".

O resgate da memória, realizado por Darcy Ribeiro, no plano ficcional, tem sua contrapartida na extensa obra antropológica do autor. O povo brasileiro, por exemplo, dialoga com a tradição antropológica brasileira que buscou explicar a formação do Brasil. Nesse texto, o autor faz um caminho inverso.Relê, no ensaio antropológico, seu próprio percurso literário. Nesse sentido, o autor não só reconstrói sua memória (pela leitura e pela reescritura de textos literários e antropológicos) como a reescreve de forma coletiva. Diários índios revela-nos que a memória impulsiona a vida e a escrita.

Diante da viagem e da memória, o leitor desloca o seu olhar, enfrentando uma floresta de signos e a noite profunda da escrita com seus insondáveis mistérios. Nessas idas e voltas, cansaço e recomeço, volto ao arquivo de Darcy, buscando mais um de seus diálogos com a França e seus fazimentos. 


\section{Darcy Ribeiro e a "Casa França-Brasil": uma breve notícia}

Em 4 de julho de 1984, Darcy Ribeiro ${ }^{53}$ é entrevistado pelo Jornal do Brasil para falar sobre sua viagem a Paris, Lisboa e Milão. Como Secretário de Ciência e Cultura do Rio de Janeiro, tinha ido acertar convênios que possibilitassem "a concretização de alguns dos projetos que ele quer ver realizados até o final de seu mandato. Entre eles, dois museus - o da presença francesa no Brasil e o da civilização portuguesa, uma biblioteca, na Praça da República, e um teatro, na Casa de Álvaro Alvim". ${ }^{54}$

Para a instalação da "Casa França-Brasil", foi restaurado o prédio "considerado a primeira edificação no estilo neoclássico francês", ${ }^{55}$ projetado pelo arquiteto francês Auguste Henri Victor Gradjean de Montigny. Pensado para guardar o "maior banco de dados possível sobre toda a história das relações entre os dois países, em todos os campos e segmentos das artes e da cultura", "funciona hoje como um importante centro de exposições no Rio de Janeiro".

\section{Conclusão}

A paisagem do "Outro" pode abrigar um acervo comum entre os dois países como a França e o Brasil. O esforço de refazer os elos da História deve ser marcado pelos olhares críticos de ambas as culturas que se projetarão não só para o passado como para o futuro em busca de trocas não desiguais, marcadas pela dependência de uma cultura em relação a outra.O trabalho com os arquivos particulares, dentre outros caminhos, pode mostrar a existência de outras trocas culturais além dos aspectos apenas exóticos. Foi o que se pretendeu evidenciar, a partir da trajetória intelectual de Darcy Ribeiro no diálogo com a França propiciado por outros atores como Carlos de Araujo Moreira Neto, Berta Ribeiro e Claude Lévi-Strauss.

53. Mais planos de Darcy Ribeiro. Museus para a nacionalidade, teatros e biblioteca para o povo. WYLER. Abertura, o livro brasileiro amplia o seu espaço na programação das editoras francesas, [s.p.].

54. WYLER. Abertura, o livro brasileiro amplia o seu espaço na programação das editoras francesas, [s.p.].

55. MOREIRA. Fazimentos. Carlos Moreira Neto, p. 24.

56. MOREIRA. Fazimentos. Carlos Moreira Neto, p. 25.

57. MOREIRA. Fazimentos. Carlos Moreira Neto. 
Darcy Ribeiro and other actors: intersections in France-Brazil dialogue

Abstract: This study highlights the dialogue between France and Brazilstarting from the intellectual journey of Darcy Ribeiro. To introduce the topic, it is shown that, according to Antonio Candido, Brazilian literature is linked to comparative literature. This means that our literature establishes relations with another literatures and also with the history, criticism and other fields of knowledge, etc.. Considering the specificity of the dialogue between Brazil and France, it is possible that this occurs since the writings of French travelers in Brazil in the sixteenth century. Referencing this aspect opens up many paths in literature, Brazilian criticism and interdisciplinary character between literature and anthropology, focus of this essay that is about the dialogue between France and Brazil, since Darcy Ribeiro was an anthropologist and novelist. His first novel was translated into French and also commented by many French newspapers. He received the title of "Doctor Honoris Causa", from Paris University, Sorbonne. He also maintained an intellectual communication and friendship with Levi Strauss who has written many anthropological books and even narrative texts as "Tristes Tropiques". As Culture Secretary of the government of Leonel Brizola, in Rio de Janeiro, he idealized the "Casa França Brasil". To develop the theme, will focus the following aspects: in the file web, the correspondence between Berta Ribeiro, Darcy Ribeiro and Lévi-Strauss, Darcy Ribeiro in France, travel, memory, and interdisciplinarity. To conclude, we will discuss the item about "Darcy Ribeiro and 'Casa França-Brasil'".

Keywords: Darcy Ribeiro, intelectual dialogue, Brazil-France 


$$
\text { Referências }
$$

CANDIDO, Antonio. Literatura comparada. In: Recortes. São Paulo: Companhia das Letras, 1993. p. 211-215.

CANDIDO, Antonio. Oswald viajante. In: Vários escritos. São Paulo: Duas Cidades, 1977. p. 53-56.

CARTA de Berta Ribeiro a Claude Lévi-Strauss. Rio de Janeiro, 7 de mar. 1969. (Arquivo Fundação Darcy Ribeiro).

CARTA de Claude Lévi-Strauss a Darcy Ribeiro. École Pratique des Hautes Études, Sorbonne, Paris, 28 oct. 1952. (Arquivo Fundação Darcy Ribeiro).

CARTA de Darcy Ribeiro a Claude Lévi-Strauss em português. Ministério da Agricultura, Seção de Estudos, Serviço de Proteção aos Índios, Rio de Janeiro, 2 jan. 1953. (Arquivo Fundação Darcy Ribeiro).

CARTA de Lévi-Strauss para Darcy Ribeiro. International Social Science Council/ Conseil International des Sciences Sociales, Paris, le 20 sept. 1954. (Arquivo Fundação Darcy Ribeiro).

CHAIX, Jean-François. Entretien. Je me suis mis dans la peau d'un Indien. Les Nouvelles Littéraires, Paris, 11-18 juin 1981. Lettres étrangères. (Arquivo Fundação Darcy Ribeiro).

CHAIX, Jean-François. Maïra de Darcy Ribeiro. Le roman antigénocide d'un anthropologue brésilien. Les Nouvelles Littéraires, Paris, p. 11-18, juin 1981. Lettres étrangères. (Arquivo Fundação Darcy Ribeiro).

DAMATTA, Roberto. Conta de mentiroso. In: brasileira. Rio de Janeiro: Rocco, 1993. 209 p. Sete ensaios de antropologia

DAMATTA, Roberto. Reflexões sobre interdisciplinaridade: uma perspectiva antropológica. In: PORTELLA, Eduardo (Org.). Iinterdisciplinaridade. Rio de Janeiro: Tempo Brasileiro, v. 113, abr.-jun. 1993. p. 35-57.

DESCAMPS, Pierre. La Gazette de la région du Nord. Lille, le 17 mars 1981. (Arquivo Fundação Darcy Ribeiro).

DIBIE, Pascal. La grande messe de l'ethnologie. Magazine Littéraire, Paris, n. 170, mars 1981. (Arquivo Fundação Darcy Ribeiro).

DIDIER, Eribon. De perto e de longe. Trad. Léa Mello e Julieta Leite. Rio de Janeiro: Nova Fronteira, 1990. 235 p.

GARDAIR, Jean Michel. Nos ancêtres les Indiens. "Mära", de Darcy Ribeiro. Combat Socialiste, Paris, 17 mars 1981, Livres. (Arquivo Fundação Darcy Ribeiro).

GILLES, Edmond. Grandeur et décadence d'une tribu d'Amazonie. A mi-chemin entre le roman et l'ethnologie. Agence Française d'Etraits de Presse, Paris, le 21 avr. 1981. Littérature brésilienne. (Arquivo Fundação Darcy Ribeiro).

GOMES, André Luís. Cartas em foco: Clarice Lispector e o teatro. O Eixo e a Roda Revista de Literatura Brasileira, Belo Horizonte, Faculdade de Letras da UFMG, v. 9/ 10, p. 97-124, 2003/2004.

LAPlANTINE, François. Aprender Antropologia. Trad. Marie Agnès Chauvel. 6. ed. São Paulo: Brasiliense, 1993. 205 p.

LE MONDE. Le professeur Darcy Ribeiro est incarcéré depuis trois mois dans une Forteresse de Rio. Paris, 5 avr. 1969, p. 4. (Arquivo Fundação Darcy Ribeiro). 
LÉVI-STRAUSS, Claude. Saudades do Brasil. Trad. Paulo Neves. São Paulo: Companhia das Letras, 1994. 225 p.

LÉVI-STRAUSS, Claude. Tristes trópicos. Trad. Gabinete Literário de Edições 70. Lisboa: Edições 70, 1993. 402 p.

MASSI, Fernando Peixoto. O nativo e o narrativo. Os trópicos de Lévi-Strauss e a África de Michel de Leiris. Novos Estudos, São Paulo: CEBRAP, n. 33, p. 187-198, jul. 1992.

MIGNOLO, Walter. Espacios geográficos y localizaciones epistemológicas o la ratio entre la localización geográfica y la subalternización de conocimientos. Cânones $e$ contextos, Anais, Rio de Janeiro, ABRALIC, 1997. p. 91-106.

MIRANDA, Wander Melo (Org.). A trama do arquivo. Belo Horizonte: Editora UFMG/ Centro de Estudos Literários da Faculdade de Letras da UFMG, 1995. 120 p.

MOREIRA, Gisele Jacon de Araújo. Fazimentos. Carlos Moreira Neto. Caderno 6, Rio de Janeiro: Fundação Darcy Ribeiro, out. 2008. 47 p.

PEIRANO, Mariza. Uma antropologia no plural: três experiências contemporâneas. Brasília: Universidade de Brasília, 1992. 265 p.

RAILLARD, Alice. Le sentiment d'être indien. Weekend. Lettres, Arts, Voyages, Paris, le 3 avr. 1981. (Arquivo Fundação Darcy Ribeiro).

RIBEIRO, Darcy. Je me suis mis dans la peau d'un indien. Entretien avec Jean François Chaix. Les Nouvelles Littéraires, Paris, 11-18 juin, 1981. Lettres étrangères. (Arquivo Fundação Darcy Ribeiro).

RIBEIRO, Darcy. Maíra. Trad. Alice Raillard. Paris: Gallimard, 1980. 392 p.

RIBEIRO, Darcy. Maíra. 5. ed. Rio de Janeiro: Civilização Brasileira, 1981. 403 p.

RIBEIRO, Darcy. Testemunbo. 2. ed. São Paulo: Siciliano, 1990. 262 p.

RIBEIRO, Darcy; MOREIRA NETO, Carlos de Araújo (Org.). A Fundação do Brasil. Testemunhos. 1500-1700. 2. ed. Petrópolis: Vozes, 1992. 447 p.

RIVAS, Pierre. Diálogos interculturais. São Paulo: Hucitec, 2005. 302 p.

SABINO, Fernando; LISPECTOR, Clarice. Cartas perto do coração. Fernando Sabino e Clarice Lispector. Rio de Janeiro: Record, 2001. 222 p.

SANTIAGO, Silviano. Viagem ao México. Rio de Janeiro: Rocco, 1995. 383 p.

SCHWARTZ, Jorge. Vanguardas enfrentadas. In: Vanguarda e cosmopolitismo. São Paulo: Perspectiva, 1978. p. 45-90.

VITOUX, Fréderic. La jungle à feu et à sang. Pour combien de temps encore les Indiens d'Amazonie verront-ils se lever le soleil? Le Nouvel Observateur, Paris, le 23 mars 1981. Lettres brésiliennes. (Arquivo Fundação Darcy Ribeiro).

WYLER, Vivian. Abertura, o livro brasileiro amplia o seu espaço na programação das editoras francesas. Jornal do Brasil, Rio de Janeiro, 25 jul. 1981. (Arquivo Fundação Darcy Ribeiro). 